\title{
EL DEBER DE REPARAR EN CONTEXTOS EXTRAORDINARIOS $Y$ TRANSICIONALES
}

Andrés Tafur Villarreal 


\section{THE DUTY TO REPAIR IN EXTRAORDINARY AND TRANSITIONAL CONTEXTS}

\section{ABSTRACT}

The present article does not have another intention rather to be an exploratory text. It proposes, in the first part, a review of some discussions on repair, as defined international law and its new interpretations in relation to its implementation in the context of massive victimization and societies well-des-ordered. The second part makes an analytic exercise limited in respect of the implementation of programs of repair in Colombia, through the Justice and Peace Law (975/2005) and the Victims and restitution of lands law (1448/2011). Starting from one and other politic, it concludes with the reflection about the Integral System of Justice, Truth, Repair and non-repetition, agreed in the negotiations of the Habana between the national government and Farc-Ep.

Key words: : transitional justice, reparation, restitution, victims

\section{AUTOR}

\section{Andrés Tafur Villarreal}

Comunicador Social y Filósofo Universidad de los Andes. Magister (C) en Ciencia Política. Universidad de los Andes. Correo electrónico: a.tafur10@uniandes.edu.co

\section{RESUMEN}

El presente artículo no tiene otra pretensión más que ser exploratorio. Se propone, en la primera parte, repasar algunas discusiones en torno a la reparación, a la luz de su definición en el derecho internacional y sus re-interpretaciones de cara a su implementación en contextos de victimización masiva y de sociedades bien des-ordenadas. $Y$ en la segunda, realizar un ejercicio analítico limitado respecto de la implementación de programas de reparación en Colombia, a través de la Ley de Justicia y Paz (975/2005) y la Ley de Víctimas y Restitución de Tierras (1448/2011). Partiendo de los alcances de una y otra política, se concluye con una reflexión sobre el Sistema Integral de Justicia, Verdad, Reparación y No Repetición, acordado en las negociaciones de La Habana entre el gobierno nacional y la guerrilla de las FARC-EP.

Palabras clave: justicia transicional, reparación, restitución, víctimas. 


\section{INTRODUCCION}

Tal vez el único consenso que vale la pena destacar de las distintas nociones de reparación repasadas en este artículo, es acerca de su importantísimo papel en la convivencia y la reconciliación en el posconflicto. Desde la perspectiva jurídica, animada por el derecho internacional, hasta las concepciones teóricas y normativas que la relacionan con el desarrollo y las transformaciones políticas, se asume que reparar a las víctimas constituye el principal precedente del éxito o el fracaso de un modelo de justicia transicional, y de la misma construcción de paz. La afirmación puede parecer polémica, en el entendido de que, en buena medida, los modelos implementados en la experiencia internacional se han centrado en los asuntos de justicia (retributiva), en virtud de su relación casi dicotómica conla posibilidad dealcanzar la pazporunavía negociada. El asunto central es que se empieza a superar cierta visión punitivista u ordinarizante de la justicia en general y de la justicia transicional en particular, para entenderla en un sentido más amplio, en sus dimensiones restaurativa y reparadora. De esa manera, si bien la penalización de los delitos graves sigue siendo un imperativo, lo es tanto como restituir, indemnizar, rehabilitar y satisfacer a las víctimas, conocer la verdad de los hechos ocurridos, hacer memoria de los agravios (y las resistencias), restablecer el tejido social destruido por la violencia, construir confianza cívica y mejorar el bienestar de los ciudadanos. Hablamos hoy - y Colombia será paradigma de eso dentro de algunos años - de modelos "holísticos" de justicia transicional, que se operan como sistema de ntro de los cuales, sus medidas y mecanismos funcionan bidireccionalmente, sirviéndose unos de otros, aunque de manera autónoma a partir de funciones cuidadosamente planificadas. El asunto, en resumen, ya no consiste en qué tanta impunidad nos podemos permitir para hacer la paz, sino qué sentido tiene una paz negociada que no satisfaga los derechos de las víctimas.

El presente artículo no tiene otra pretensión más que ser exploratorio. Se propone, en la primera parte, repasar algunas discusiones en torno a la reparación, a la luz de su definición en el derecho internacional y sus re-interpretaciones de cara a su implementación en contextos de victimización masiva y de sociedades "bien des-ordenadas" (Uprimny \& Saffon, 2009). Y en la segunda, realizar un ejercicio analítico limitado respecto de la implementación de programas de reparación en Colombia, a través de la Ley de Justicia y Paz (975/2005) y la Ley de Víctimas y Restitución de Tierras (1448/2011). Partiendo de los alcances de una y otra política, se concluye con una reflexión sobre el Sistema Integral de Justicia, Verdad, Reparación y No Repetición, acordado en las negociaciones de La Habana entre el gobierno nacional y la guerrilla de las Farc-Ep.

Frente a las medidas acordadas en este último para reparar a las víctimas, quedan abiertas varias preguntas: ¿Se obligará a los perpetradores a reparar a sus víctimas o será el Estado como subsidiario el que termine asumiendo el costo total de las reparaciones? ¿Qué futuro tendrá la reparación individual por vía de indemnizaciones judiciales y administrativas, en un contexto de déficit fiscal como el que atraviesa el Estado colombiano? ¿Cómo avanzar firmemente en el proceso de restitución de tierras de cara a la enconada oposición que protagonizan distintos sectores políticos y militares, legales e ilegales? ¿Asumirán los terceros implicados (financiadores, testaferros, etc.) en el conflicto armado la obligación de reparar a las víctimas?

Como puede apreciarse el tema no es menor, y promete encarnar los grandes debates de la paz en el corto, mediano y largo plazo. 
PERSPECTIVAS JURÍDICAS. POLÍTICAS Y ECONÓMICAS DE LA REPARACIÓN

\section{Sistema internacional contra la impunidad y la reparación de las víctimas}

La preocupación por la reparación se encuentra estrechamente vinculada a la de la impunidad, en clave de los procesos transicionales de justicia que enfrentan las sociedades que dejan atrás episodios sistemáticos de victimización. Los primeros estudios sobre reparaciones aparecen en un contexto en el que se empiezan a producir cambios políticos en distintos continentes, en dirección de mejorar la situación de los derechos humanos a nivel mundial. Ese contexto también coincide con la implementación de los primeros mecanismos de justicia transicional (JT) en algunos países en los que, restablecer la justicia, significó, por una parte, poner mayor énfasis en la responsabilidad penal de los perpetradores de violaciones manifiestas de los derechos humanos (ddhh) y sus cómplices, y por la otra, poner en evidencia los daños causados a las víctimas de esas violaciones, con miras a ofrecerles una justicia retributiva y reparadora. Los denominados Principios Joinet, base jurídico-política de la JT, recogen el acumulado de las luchas contra la impunidad, agenciadas por diversas organizaciones de la sociedad civil que se organizaron en torno al rechazo de las leyes de perdón y olvido, y la exigencia de la verdad y la reivindicación de las víctimas de los totalitarismos ${ }^{1}$. Luego, era apenas apropiado, que en un contexto de búsqueda de una justicia de transición y como respuesta a un clima de mayor conciencia en materia de derechos humanos, [se] iniciara (...) la preparación de estudios orientados, respectivamente, a combatir la impunidad y fortalecer el derecho de las víctimas a obtener desagravio y reparación (Van Boven, 2010, p.1) ${ }^{2}$.

La resolución de Naciones Unidas sobe los Principios y directrices mantiene esa línea. Luego de quince años de negociaciones y debates, el principio de la reparación continuó aunado al de la lucha contra la impunidad ${ }^{3}$. De acuerdo con Arthur (2011), teniendo en cuenta que en el origen de la JT, como campo, se encontraba el anhelo de transición de la dictadura a la democracia, las cuestiones de justicia fueron diseminadas entre la

\footnotetext{
${ }^{1}$ De constituir una bandera reivindicativa en contra de las dictaduras del Cono Sur en los años 70, las demandas sociales de amnistía de los presos políticos se convirtieron en leyes de auto-amnistía de los propios dictadores, quienes, en virtud de las mismas, pretendieron auto-indultarse de las graves violaciones a los DDHH cometidas con ocasión del ejercicio autoritario del poder. Como reflejo de la lucha de las víctimas, la Corte Interamericana de Derechos Humanos, Corte IDH, consideró que la amnistía de los autores de graves violaciones de los derechos humanos era incompatible con el derecho que toda persona tiene, en condiciones de plena igualdad, a ser oída por un tribunal imparcial e independiente. La Conferencia Mundial de Derechos Humanos de 1993 fomentó esa tendencia en su declaración final, titulada "Declaración y Programa de Acción de Viena". El Informe Joinet se enmarca, por tanto, en la aplicación del Programa de Acción de Viena y recomienda, a tales efectos, la aprobación por la Asamblea General de las Naciones Unidas de un conjunto de principios para la protección y la promoción de los DDHH mediante la lucha contra la impunidad. Estos principios son: verdad, justicia, reparación y garantías de no repetición, que al mismo tiempo constituyen derechos de las víctimas a saber, a que se haga justicia, a obtener reparación y a que lo sucedido no vuelva a ocurrir. Una historia conceptual de la JT se encuentra en Arthur (2011).

2 Desde 1989 hasta 2005, año en que la ONU adoptó los "Principios y directrices básicos sobre los derechos de las víctimas de violaciones manifiestas de las normas internacionales de derechos humanos y violación al derecho internacional humanitario a interponer recursos y obtener reparaciones" (en adelante "los Principios y directrices"), se prepararon seis informes, entre otros documentos, relativos al derecho de restitución, indemnización y rehabilitación de las víctimas de violaciones graves de los ddhh y las libertades fundamentales. La tabla 1 , en anexos, presenta el orden cronológico de los informes y sus relatores.

${ }^{3}$ Ese mismo año la entonces Comisión de Derechos Humanos de las Naciones Unidas (que fue reemplazada por el Consejo de Derechos Humanos en 2006) hizo suyo el conjunto de principios actualizado para la protección y la promoción de los derechos humanos mediante la lucha contra la impunidad (E/CN.4/2005/102/Add.1).
} 
obligación (moral) de condenar a los perpetradores de delitos graves y en el imperativo de proporcionar alguna medida de compensación a aquellos que sufrieron bajo los regímenes de un Estado represivo (2011, p. 116). La cuestión es que este criterio no solamente sustentó la posición de la Asamblea General de las Naciones Unidas, sino que también constituyó el desarrollo jurisprudencial de la Corte Interamericana de Derechos Humanos - Corte IDH - y el estatuto de la Corte Penal Internacional - CPI-. Es esto lo que permite hablar de una "jurisdicción universal" y de un sofisticado y robusto sistema de derecho internacional contra la impunidad y la reparación de las víctimas (Cuadro 1).

De acuerdo con Van Boven, algunas de las principales cuestiones que se plantearon durante el proceso de debate y negociación de la resolución de los Principios y directrices, fueron, entre otras:

A. Sobre la responsabilidad del Estado: en este aspecto, los Principios y directrices son deudores del proyecto de codificación de la responsabilidad internacional de los Estados por el hecho internacionalmente ilícito ${ }^{4}$. Aunque el modelo de reparación fue concebido originalmente entre Estados y no entre Estados y personas, fue en virtud de que los ddhh empezaron a ser ratificados en diversos tratados, aunado a la mala conducta (ampliamente reconocida) de diversos gobiernos, que fue posible hacer valer el derecho a una efectiva reparación por violaciones (manifiestas) de los ddhh, a la luz del derecho internacional consuetudinario.

B. Sobre normas de ddhh y DIH: según Van Boven, la opinión general fue que "dado que los Principios y directrices estaban orientados a las víctimas y se basaban en la solidaridad social y humana, debía entenderse que no se proponían reflejar las diferencias jurídicas que existían entre las violaciones de las normas internacionales de derechos humanos y las violaciones del derecho internacional humanitario" (2010, p. 2). De esta manera, se consideró que aunque estas dos ramas del derecho internacional habían evolucionado por vías jurídicas e históricas distintas, se solapaban en algunos aspectos en los cuales podían ofrecer protección complementaria a las víctimas.

C. Violaciones flagrantes o todas las violaciones: los primeros estudios utilizaron el término "flagrante" (Ver tabla 1 en anexos) para calificar las violaciones y el tipo de derecho violado (ddhh y libertades fundamentales). En los debates y negociaciones se criticó este enfoque, dado que restringía el derecho de interponer recursos y obtener reparación por todas las violaciones a los ddhh. Como, por otra parte, los Principios y directrices también incluían las violaciones al DIH, se impuso el punto de vista de que el documento debía centrarse en las violaciones más severas. Según Van Boven, los autores tenían en mente las violaciones que

\footnotetext{
${ }^{4}$ Fue finalmente promulgado por la Asamblea General de las Naciones Unidas en la Resolución 56/83 de 2001 , aunque, de acuerdo con Santamaría (2014), la codificación comenzó a ser desarrollada desde 1956 en el seno de la Comisión de Derecho Internacional. El concepto de reparación incorporado en esta resolución, compromete tres conceptos distintos pero complementarios entre sí: $\mathbf{1}$. La restitución: "el Estado responsable está obligado a restablecer la situación que existía antes de la comisión del hecho ilícito, siempre y cuando esa restitución: a. No sea materialmente imposible, b. No entrañe una carga totalmente desproporcionada con relación al beneficio que derivaría de la indemnización en vez de la restitución (Art. 35)" 2. La indemnización: pago del valor pecuniario por el daño causado, "(...) en la medida que dicho daño no sea reparado por la restitución, y que cubra todo daño susceptible de valoración económica (...)” (Art. 36) 3. La satisfacción: “(...) satisfacer el perjuicio causado por el hecho ilícito, en la medida en que ese perjuicio no haya podido ser reparado mediante restitución o indemnización, y que puede consistir en un reconocimiento de la violación, una expresión de pesar, una disculpa formal o cualquier otra modalidad adecuada que no sea desproporcionada con relación al perjuicio, aunque esta no puede adoptar una forma humillante para el Estado responsable (...)" (Art. 37).
} 
constituían crímenes internacionales con arreglo al Estatuto de Roma de la Corte Penal Internacional -CPI5-.

Al final, se acordó que si bien los Principios y directrices hacen hincapié en las violaciones "manifiestas" y "graves", "generalmente se reconoce que en principio todas las violaciones de los derechos humanos y del derecho internacional humanitario acarrearán consecuencias jurídicas" (2010, p. 3), y por ende, el derecho a interponer recursos y obtener reparaciones.

D. Sobre la noción de víctima: los Principios y directrices acogieron el concepto de víctima adoptado en la Declaración sobre los principios fundamentales de justicia para las víctimas de delitos y del abuso de poder, aprobados en 1985 por la Asamblea General de las Naciones Unidas (resolución 40/34). Con arreglo a esa definición, "una persona es víctima si ha sufrido lesiones físicas o mentales, pérdida financiera o menoscabo sustancial de sus derechos fundamentales" (p. 3). No solamente son víctimas quienes sufren la agresión de manera directa, sino que pueden serlo también de manera indirecta, por ejemplo, tratándose de familiares o personas a cargo de la víctima directa y pueden haber sufrido daños individual o colectivamente.

E. Agentes no estatales: se refiere a "movimientos o grupos que ejercen un control efectivo sobre ciertos territorios y la población de esos territorios, pero también en relación con empresas que ejercen poder económico" (p. 4). Aunque los Principios y directrices fueron elaborados sobre la base de la responsabilidad estatal, esto no obsta para que los agentes no estatales sean responsabilizados por sus "políticas y prácticas", "lo que permitiría a las víctimas interponer recursos e intentar obtener reparación sobre la base de la responsabilidad jurídica y la solidaridad humana, y no sobre la base de la responsabilidad del Estado" (p. 4).

Los consensos alrededor de estas cuestiones representan la base conceptual, jurídica y política de los Principios y directrices y, así mismo, encarnan los postulados de sus distintas secciones. Entre los derechos de las víctimas a interponer recursos, la Resolución contempla: a) acceso igual y efectivo a la justicia, b) reparación adecuada, efectiva y rápida del daño sufrido, y c) acceso a información pertinente sobre las violaciones y los mecanismos (2005, p.12) ${ }^{6}$. Una reparación adecuada, efectiva y rápida tiene por finalidad promover la justicia. Desde este punto de vista, se conmina a los Estados a establecer programas nacionales de reparación (p.16), a ejecutar las sentencias de sus tribunales que impongan reparaciones a las personas o entidades responsables de los daños sufridos (p. 17), y, finalmente, conforme al derecho interno y al derecho internacional, y teniendo en cuenta las circunstancias de cada caso, de forma apropiada y proporcional a la gravedad de la violación, a garantizar una reparación plena y efectiva en las formas siguientes: restitución, indemnización, rehabilitación, satisfacción y garantías de no repetición.

A. La restitución se refiere a la medida en que se

\footnotetext{
5 "Esas disposiciones reafirman que los Estados tienen la obligación de investigar y, si hay pruebas suficientes, enjuiciar a las personas presuntamente responsables de esas violaciones y, si se las declara culpables, la obligación de castigarlas (principio 4). También incluyen la obligación de incorporar disposiciones apropiadas relativas a la jurisdicción universal (principio 5), así como referencias a la imprescriptibilidad de esas violaciones (principios 6 y 7$)^{\prime \prime}(2010$, p. 3).

${ }^{6}$ En adelante, todas las citas tomadas de los informes y resoluciones de Naciones Unidades harán referencia al párrafo, no a la página. Así, la cita de la Resolución de los Principios y directrices es tomada literalmente del párrafo 12, y no corresponde a la página del párrafo, que es la número 7.
} 
puede "devolver a la víctima a la situación anterior a la violación manifiesta de las normas internacionales de derechos humanos o la violación grave del derecho internacional humanitario" (p.19). La restitución comprende el restablecimiento de la libertad, el disfrute de los derechos humanos, la identidad, la vida familiar y la ciudadanía, el regreso al lugar de residencia, la reintegración en el empleo y la devolución de bienes.

B. La indemnización "ha de concederse, de forma apropiada y proporcional a la gravedad de la violación y a las circunstancias de cada caso, por todos los perjuicios económicamente evaluables" (p.20). El daño que dé lugar al pago de una indemnización puede ser consecuencia de un daño físico o mental, la pérdida de oportunidades, en particular las de empleo, educación y prestaciones sociales; perjuicios morales, gastos de asistencia jurídica o de expertos, medicamentos y servicios médicos, y servicios psicológicos y sociales.

C. La rehabilitación incluyeatención médicaypsicológica, así como servicios jurídicos y sociales (p. 21).

D. La satisfacción incluye una paleta amplia, desde la adopción de medidas para que cesen las violaciones hasta la revelación de la verdad, la búsqueda de las personas desaparecidas, la recuperación de cadáveres y su nueva inhumación, disculpas públicas, sanciones judiciales o administrativas, conmemoraciones y enseñanza de las normas de derechos humanos (p. 22).

E. Las garantías de no repetición incluyen amplias medidas estructurales de naturaleza normativa, como reformas institucionales orientadas a asegurar el control civil de las fuerzas militares y de seguridad, el fortalecimiento de la independencia judicial, la protección de los defensores de los derechos humanos, la promoción de la observancia de las normas de derechos humanos en la administración pública, las fuerzas de seguridad, los medios de información, y los servicios psicológicos y sociales (p. 23).

En el Preámbulo de los Principios y directrices, la Asamblea General suscribe el requerimiento del Estatuto de Roma, en el sentido de establecer disposiciones que reconozcan el derecho a un recurso a las víctimas de violaciones de las normas internacionales de ddhh, así como a los "principios aplicables a la reparación, incluidas la restitución, la indemnización y la rehabilitación" (2005, pág. 2, 3). Este requerimiento de la CPI no está desconectado de los debates y las negociaciones internacionales en torno de la interposición de recursos y la obtención de reparaciones descrito anteriormente, de hecho, se encuentra profundamente integrado. Según Van Boven (2010), en la formulación del Estatuto de la CPI aprobado en la Conferencia Diplomática celebrada en Roma en 1998, particularmente en el artículo 75 sobre reparación a las víctimas, quedó reflejada la intención y la redacción del (entonces) proyecto de Principios y directrices:

Artículo 75. Reparación a las víctimas: 1. La Corte establecerá principios aplicables a la reparación, incluidas la restitución, la indemnización y la rehabilitación, que ha de otorgarse a las víctimas o a sus causahabientes. Sobre esta base, la Corte, previa solicitud o de oficio en circunstancias excepcionales, podrá determinar en su decisión el alcance y la magnitud de los daños, pérdidas o perjuicios causados a las víctimas o a sus causahabientes, indicando los principios en que se funda (...) (Estatuto de Roma, 1998, p. 44).

Por su parte, la Corte IDH, y la Comisión Interamericana de Derechos Humanos, se acogen a las disposiciones 
del Sistema Interamericano de Derechos Humanos, fundado en la Convención de 1969. Cualquier conducta imputable a un Estado y que resulte en una violación de sus compromisos internacionales asumidos en materia de ddhh engendra el nacimiento de su responsabilidad en el plano internacional. Nace, entonces, la relación jurídica consistente en la obligación de reparar el daño causado. En el Sistema Interamericano, las reparaciones tienen respaldo convencional. La facultad de la Corte IDH para exigir reparaciones está prevista en el artículo 63.1 de la Convención, el cual dispone:

Artículo 63. 1. Cuando decida que hubo violación de un derecho o libertad protegidos en esta Convención, la Corte dispondrá que se garantice al lesionado en el goce de su derecho o libertad conculcados. Dispondrá asimismo, si ello fuera procedente, que se reparen las consecuencias de la medida o situación que ha configurado la vulneración de esos derechos y el pago de una justa indemnización a la parte lesionada.
A través de los años, y de los casos, el Sistema Interamericano ha desarrollado criterios avanzados en materia de reparación que, sin desconectarse de la clasificación de los Principios y directrices (restitución, indemnización, rehabilitación, satisfacción y garantías de no repetición), establecen un "nuevo paradigma legal de justicia" mediante la interacción entre recursos penales y civiles, así como con la necesidad de adecuar las instituciones estatales para prevenir violaciones de los derechos humanos. Esto supone, por un lado, ir más allá de la mirada puramente indemnizatoria de la reparación, y por otro, considerar ya no solamente la reparación individual sino la concurrencia de casos masivos de victimización.

\section{Justicia y reparaciones}

Hasta ahora, el horizonte de sentido de las reparaciones ha estado influenciado por la dimensión jurídica

\begin{tabular}{|c|c|c|c|}
\hline \multicolumn{4}{|c|}{ Cuadro 1: Sistema internacional contra la impunidad y la reparación de las víctimas } \\
\hline \multirow[b]{2}{*}{ Naciones Unidas } & \multirow[b]{2}{*}{$\begin{array}{l}\text { Corte Penal } \\
\text { Internacional }\end{array}$} & \multicolumn{2}{|c|}{$\begin{array}{l}\text { Sistema Interamericano de Derechos } \\
\text { Humanos }\end{array}$} \\
\hline & & $\begin{array}{l}\text { Corte } \\
\text { Interamericana de } \\
\text { Derechos Humanos }\end{array}$ & $\begin{array}{l}\text { Comisión } \\
\text { Interamericana de } \\
\text { Derechos Humanos }\end{array}$ \\
\hline Principios y directrices... & \multirow[t]{4}{*}{$\begin{array}{l}\text { Estatuto de } \\
\text { Roma }\end{array}$} & \multicolumn{2}{|c|}{$\begin{array}{l}\text { Convención Interamericana de Derechos } \\
\text { Humanos (Jurisdicción universal). }\end{array}$} \\
\hline $\begin{array}{l}\text { Los Principios para la protección y la } \\
\text { promoción de los Derechos Humanos } \\
\text { mediante la lucha contra la impunidad }\end{array}$ & & \multicolumn{2}{|c|}{$\begin{array}{l}\text { Lineamientos principales para una política } \\
\text { integral de reparaciones (Comisión IDH) }\end{array}$} \\
\hline $\begin{array}{l}\text { La Declaración de las Naciones Unidas } \\
\text { sobre los Principios fundamentales de } \\
\text { Justicia para las Víctimas de Delitos y del } \\
\text { Abuso de Poder }\end{array}$ & & \multicolumn{2}{|c|}{ Jurisprudencia (Corte IDH) } \\
\hline \multirow[t]{2}{*}{$\begin{array}{l}\text { La Resolución sobre la Responsabilidad } \\
\text { de los Estados por hechos } \\
\text { internacionalmente ilícitos }\end{array}$} & & & \\
\hline & & \multicolumn{2}{|c|}{ Fuente: elaboración propia } \\
\hline
\end{tabular}


del término. Esto en sí mismo no representa un problema, no obstante que está pensada en el contexto de casos aislados o, en todo caso, individuales. La reflexión de De Greiff (2011) apunta a que se considere de manera independiente la cuestión de la justicia en la reparación en "casos masivos y sistemáticos de abuso" (de Greiff, 2011, p. 408). Para ello parte de una aclaración semántica: el uso del término de acuerdo a dos contextos distintos:

El jurídico, especialmente el contexto del derecho internacional, en el cual el término se emplea en un sentido amplio para referirse a todas aquellas medidas que se pueden adoptar para resarcir los diversos tipos de daño que puedan haber sufrido las víctimas como consecuencia de ciertos crímenes (De Greiff, 2011, p. 409).

La amplitud del término en este contexto comporta las diversas formas como se entienden las reparaciones en el derecho internacional, es decir, como restitución, compensación, rehabilitación, satisfacción y garantías de no repetición. El siguiente contexto de uso del término es el del diseño de programas de cobertura masiva:

\begin{abstract}
En este contexto, ya pesar de las relaciones que cada uno de estos programas pueda tener con otros esfuerzos por obtener justicia, el término se utiliza en un sentido más restringido. Aquí, el término 'reparaciones' se refiere a los esfuerzos para ofrecer beneficios directamente a las víctimas de cierto tipo de crímenes. En este sentido, los programas de reparaciones no consideran la revelación de la verdad, la justicia penal o la reforma institucional, por ejemplo, como parte de las reparaciones. (De Greiff, 2011, p. 409).
\end{abstract}

Las diferencias fundamentales entre uno y otro contexto emergen de la forma como cada cual interpreta las categorías de justicia y reparación. En este sentido, según de Greiff, las dos distinciones fundamentales son entre reparaciones materiales y simbólicas, y entre la distribución individual o colectiva de cualquier clase de estas. Las reparaciones materiales adoptan la forma de compensaciones, de pagos, a través de efectivo, instrumentos negociables o de paquetes de servicios, como educación, salud y vivienda. Las reparaciones simbólicas incluyen "disculpas oficiales, rehabilitación, el cambio de nombre de espacios públicos, la creación de días de conmemoración, la construcción de museos y parques dedicados a la memoria de las víctimas, etc." (2011, p. 411). Las reparaciones individuales exigen una identificación precisa de las personas que tienen derecho a ellas, así como una manera de entregar beneficios concretos a los beneficiarios individuales, lo cual las hace "necesariamente selectivas, de manera que, en un grupo o comunidad determinados, algunas víctimas tendrán derecho a reparaciones individuales mientras otras, bien sea víctimas o conciudadanos, no lo tendrán" (ICTJ, s.f). Las reparaciones colectivas se centran en entregar beneficios a personas que han padecido violaciones de derechos humanos como grupo, de esta manera "pretenden ofrecer una respuesta efectiva a los daños ocasionados a la infraestructura comunitaria, a su identidad y confianza (...) para promover una vida comunitaria renovada y la gobernabilidad" (ICTJ, s.f).

El esfuerzo de De Greiff se centra en criticar la pretensión de trasplantar el enfoque y el ideal de la reparación individual (en proporción al daño) a casos masivos y sistemáticos de abuso. Básicamente por dos razones: 1. por la imposibilidad de que un programa de reparación asuma el criterio de reparar en proporción al daño sufrido (tal como lo entiende de derecho internacional), lo cual compromete problemas elementales de cuantificación de los distintos tipos de daño y termina generando expectativas irrealizables en las víctimas y en la sociedad en general. Y 2. por la 
diferencia de conceder reparaciones sobre la base de un modelo de justicia "colmado por el objetivo de reparar el daño particular sufrido por la víctima particular cuyo caso se presenta ante el tribunal", y el de un programa de reparaciones que se ocupa de casos masivos cuyo interés en la justicia "exige más que el intento de resarcir los daños particulares sufridos por personas particulares" para ocuparse también de las condiciones previas para "reconstruir el Estado de derecho, objetivo que tiene una dimensión pública, colectiva" (2011, p. 419).

El objetivo de "reconstruir el Estado de derecho" instala la reparación en el plano político y la expulsa de la dimensión puramente jurídica ${ }^{7}$. Esto es, en términos de De Greiff, hacer de las reparaciones un "proyecto político", cuyos objetivos generales, en relación con la justicia, serían tres: el reconocimiento, la confianza cívica y la solidaridad social. No me concentraré en cada uno de ellos, para resaltar los ideales de integridad y coherencia que el autor imagina para los programas de reparaciones. Esta característica es analizada en dos dimensiones diferentes: la externa y la interna. La coherencia externa expresa la necesidad de que los programas sean diseñados de tal manera que guarden una "estrecha relación con los otros mecanismos transicionales, esto es, con la justicia penal, el esclarecimiento de la verdad y la reforma institucional," tanto a nivel pragmático como a nivel conceptual. Esto, porque les asiste la obligación de ser percibidos como exitosos, además de que, en medio de sus limitaciones, logren satisfacer las expectativas de los ciudadanos. La coherencia interna alude a la relación de complementariedad que debe existir entre los beneficios y componentes que el plan de reparaciones ofrece. Esto significa que el alcance de los objetivos deseados debe partir de un plan de beneficios cuyos elementos se apoyen mutuamente. Nos aproximamos, desde este punto de vista, a la postulación de un modelo "holístico" de JT, cuyos mecanismos deben ser operados de manera complementaria o bidireccional ${ }^{8}$.

\section{Reparaciones transformadoras, justicia distributiva y profundización democrática}

Uprimny y Saffon (2009) dan un nuevo giro al concepto de reparación, al vincularlo con la realidad de las víctimas en sus contextos de victimización. Hasta ahora hemos discutido acerca de los usos jurídicos y administrativos del término sin observar las sociedades concretas en donde se llevan a cabo los procesos de reparación ${ }^{9}$. El cuestionamiento de Uprimny y Saffon tiene que ver con el reto de reparar en sociedades que antes del trauma de una guerra o una dictadura

El argumento del autor es el que sigue: “(...) en el contexto jurídico, el significado del término está vinculado con el objetivo específico que se busca en escenarios judiciales, que es obtener justicia para personas individuales, ahí donde los medios para alcanzar la justicia, a saber, el enjuiciamiento de casos aislados, tienen un impacto sobre el contenido concreto de la justicia. Esta aproximación al concepto de justicia difiere significativamente de aquella que pueden y deben adoptar las personas responsables de diseñar programas de reparaciones. Los tribunales no tienen más opción que considerar cada caso en sus propios términos. Por el contrario, quienes están encargados de diseñar un programa masivo de reparaciones deben responder a un universo de víctimas más amplio y complejo, y deben utilizar, necesariamente, métodos y formas de reparación adecuados a estas circunstancias. Aun cuando las reparaciones son medidas legales bien establecidas en diferentes sistemas en todo el mundo, en los períodos de transición las reparaciones buscan, en última instancia, como lo hacen la mayor parte de las medidas transicionales, contribuir (modestamente) a la reconstitución o constitución de una nueva comunidad política. En este sentido también, la mejor manera de concebirlas es como parte de un proyecto político" (2011, p. 412).

${ }^{8}$ De Greiff refinará este planteamiento en su informe como relator especial de la ONU Sobre la promoción de la verdad, la justicia, la reparación y las garantías de no repetición (2012).

La elaboración conceptual de Orozco (2002, 2009) también es clave en dirección de caracterizar el tipo de transición que enfrentan las sociedades que avanzan hacia la paz o hacia la democracia, si es desde la guerra o desde la dictadura, así como los modelos de victimización que se desprende de estas, sean horizontales o verticales, y las "zonas grises" entre una y otra. 
eran en sí mismas "excluyentes y desiguales" (2009, p. 31). El punto es que la definición usual de reparación, como se la ha entendido en el uso jurídico del término-restablecer de maneraintegraly proporcionalel statu quo ex ante de la víctima - puede ser pertinente en casos aislados de sociedades "bien ordenadas", no obstante, según los autores, dicha perspectiva puede ser problemática aplicada a violaciones masivas de ddhh en sociedades "bien desordenadas"10, esto es, sociedades

... que han enfrentado una crisis política y humanitaria profunda y que ya eran desiguales antes de la crisis humanitaria, sobre todo cuando, como es usual, los procesos de victimización han afectado esencialmente a las poblaciones pobres y excluidas (...) [en ese sentido] el enfoque puramente restitutivo de las reparaciones resulta limitado, porque pretende devolver a las víctimas a una situación de vulnerabilidad y carencias. De esa manera, no atiende a los factores estructurales del conflicto, cuya transformación es esencial no sólo para garantizar la no repetición de las atrocidades, sino porque es necesaria la superación de una situación estructuralmente injusta en términos de justicia distributiva (Uprimny \& Saffon, 2009, p. 32, 33).

En las mismas coordenadas que el modelo propuesto por de Greiff descrito anteriormente - aunque en una perspectiva diferente - Uprimny y Saffon van más allá del plano jurídico para asumir las reparaciones como un proyecto político. De esta manera, las reparaciones podrían ser comprendidas como un mecanismo no sólo de justicia transicional sino también de justicia distributiva, "puesto que se trataría de repensar la distribución justa de los bienes y las cargas en esas sociedades en transición de la guerra a la paz o de la dictadura a la democracia" (2009, p. 36). En esta dirección, la noción de "reparaciones transformadoras" trata de mirar las reparaciones

no sólo como una forma de justicia correctiva, que busca enfrentar el sufrimiento ocasionado a las víctimas y a sus familiares por los hechos atroces, sino también como una oportunidad de impulsar una transformación democrática de las sociedades, a fin de superar situaciones de exclusión y desigualdad que, como en el caso colombiano, pudieron alimentar la crisis humanitaria y la victimización desproporcionada de los sectores más vulnerables y que en todo caso resultan contrarias a principios básicos de justicia (Uprimny \& Saffon, p. 34)

El otro componente clave en la reflexión de estos autores, es la diferenciación que hacen entre la reparación, la política social y la atención humanitaria (Tabla 2). Mientras que la política social tendría como fundamento el deber del Estado de "garantizar la igualdad real o material en favor de las poblaciones vulnerables" ${ }^{\prime 11}$, consistente en otorgar un acceso privilegiado a los derechos económicos, socialesyculturalesatalespoblaciones, tradicionalmente marginadas y en condición de desigualdad estructural; el propósito de la atención humanitaria es "ofrecer una ayuda temporal a las víctimas de desastres (derivados de catástrofes naturales o de conflictos armados), tendiente a garantizar su subsistencia, aliviar su sufrimiento y proteger su dignidad y derechos fundamentales en situaciones de crisis" (2009, p. 45).

\footnotetext{
${ }^{10}$ Los autores comparan el caso de Chile y Uruguay, en donde "la devolución de las víctimas a la situación anterior a la violación implica el restablecimiento de sus derechos y de su condición de ciudadanas incluidas en la comunidad política", y los de Guatemala, Perú o Colombia, que "antes de las atrocidades eran en sí mismas excluyentes y desiguales, y cuyas víctimas pertenecían en su mayoría a sectores marginados o discriminados" (Uprimny \& Saffon, 2011, p. 33)

${ }^{11}$ Aunque sus medidas son por esencia temporales, sostienen los autores, su temporalidad puede ser bastante prolongada o aun indefinida en situaciones en las que-como sucede en el desplazamiento forzado de personas- la crisis humanitaria no parece tener un fin cercano. (p. 46).
} 
Por su parte, la reparación integral, está en función de las víctimas de crímenes atroces y su deber consiste en "reparar tales daños a través de diversos mecanismos, como la restitución, la indemnización, la rehabilitación, la satisfacción y las garantías de no repetición, de forma tal que los efectos de los mismos desaparezcan y que se restablezca la dignidad de las víctimas" (p. 46).

\section{Reparaciones y desarrollo}

Lo anterior deja en el tintero la pregunta por los vínculos específicos que pueden existir entre reparación y desarrollo, en un contexto de posconflicto armado o luego de una transición política. Roht-Arriaza y Orlovsky (2011) consideran que reparar, bajo la metodología

\begin{tabular}{|c|c|c|c|c|c|}
\hline & Origen fáctico & $\begin{array}{l}\text { Bases } \\
\text { normativas }\end{array}$ & Propósito & Beneficiarios & Mirada temporal \\
\hline $\begin{array}{l}\text { Asistencia } \\
\text { humanitaria }\end{array}$ & $\begin{array}{l}\text { Catástrofe o } \\
\text { emergencia }\end{array}$ & $\begin{array}{l}\text { Principio de } \\
\text { solidaridad y } \\
\text { deberes de } \\
\text { protección del } \\
\text { Estado }\end{array}$ & $\begin{array}{l}\text { Mitigar el riesgo y } \\
\text { reducir } \\
\text { vulnerabilidades }\end{array}$ & $\begin{array}{l}\text { Personas en } \\
\text { crisis }\end{array}$ & $\begin{array}{l}\text { Ahora y hoy, pues la } \\
\text { atención es urgente }\end{array}$ \\
\hline Política social & $\begin{array}{l}\text { Situaciones de } \\
\text { pobreza, } \\
\text { exclusión y } \\
\text { desigualdad }\end{array}$ & $\begin{array}{l}\text { Justicia } \\
\text { distributiva y } \\
\text { deberes } \\
\text { estatales } \\
\text { frente a los } \\
\text { DESC }\end{array}$ & $\begin{array}{l}\text { Satisfacer } \\
\text { necesidades } \\
\text { materiales básicas }\end{array}$ & Pobres & $\begin{array}{l}\text { Hoy, para el } \\
\text { contenido esencial } \\
\text { de los DESC y la } \\
\text { identificación de los } \\
\text { beneficiarios. En el } \\
\text { futuro, para la } \\
\text { realización } \\
\text { progresiva de los } \\
\text { DESC }\end{array}$ \\
\hline Reparaciones & $\begin{array}{l}\text { Ofensas } \\
\text { graves y } \\
\text { violaciones de } \\
\text { derechos } \\
\text { humanos y } \\
\text { DIH }\end{array}$ & $\begin{array}{l}\text { Justicia } \\
\text { correctiva y } \\
\text { deber de } \\
\text { reparar }\end{array}$ & $\begin{array}{l}\text { Borrar en lo } \\
\text { posible las } \\
\text { consecuencias de } \\
\text { la ofensa }\end{array}$ & Víctimas & $\begin{array}{l}\text { Ayer, pues se trata } \\
\text { de corregir los } \\
\text { efectos de un hecho } \\
\text { pasado }\end{array}$ \\
\hline
\end{tabular}

Fuente: Uprimny y Saffon, 2009. 
judicial o administrativa, puede ser útil al desarrollo, si se lo entiende de manera amplia como condición para que todas las personas alcancen su gama más completa de capacidades (Sen, 1999) ${ }^{12}$. Descontando las tensiones que se pueden presentar entre los programas, fundamentalmente en materia institucional, de agendas y recursos, las autoras valoran sus potenciales sinergias, tanto en plano individual como en el colectivo.

Desde el punto de vista de las reparaciones - en el plano individual y colectivo - un programa bien diseñado e implementado puede producir efectos positivos para el desarrollo en varios aspectos: 1. Permiten avanzar en el objetivo del reconocimiento de las víctimas como ciudadanos de derechos, al tiempo que ayudan a restablecer la "confianza cívica" en las instituciones. Estas serían, a juicio de las autoras, "precondiciones para una (re) emergencia de las víctimas y sobrevivientes como actores con iniciativa, motivación y confianza en un futuro que conduzca a una actividad económica sostenible" (2011, p. 527). 2. Los pagos por reparación tendrían efectos potencialmente positivos sobre "las relaciones de poder dentro de las familias y en las comunidades locales", del mismo modo que podrían "desatar la energía y creatividad de sectores previamente marginalizados", como las mujeres y los indígenas. 3. Las reparaciones en forma de servicios pueden mejorar la salud, educación y otros indicadores de bienestar que son esenciales para el desarrollo en modos que los programas "normales" para la prestación de estos servicios pasan por alto, pues no están familiarizados con el potencial específico y las necesidades de los sobrevivientes, incluyendo la necesidad de que se les reconozcan daños particulares (Roht-Arriaza \& Orlovsky, 2011, 527) ${ }^{13}$. 4. Contribuyen a mejorar la capacidad del Estado para ser un eficiente proveedor de servicios, en temas como el registro civil y la titulación efectiva.

De otro lado, desde el punto de vista del desarrollo, también se puede contribuir a una mejor habilidad para proporcionar reparaciones efectivas: 1 . En la gestión y distribución eficiente de los recursos, así como en el fortalecimiento de la presencia institucional en todo el territorio. Un país pobre con pocos recursos de infraestructura gubernamental enfrentará serias dificultades para financiar y repartir reparaciones que uno más rico y organizado. De acuerdo con las autoras, muchas reparaciones, especialmente los servicios en especie, requieren de un sistema de distribución. "En cuanto estos servicios puedan ser canalizados a través de sistemas de pensiones, de educación o de salud ya existentes, es más probable que se puedan proveer diligentemente" (2011, p. 528). 2. los esfuerzos enfocados en la lucha contra la corrupción, en términos de reforma administrativas y de seguridad, podrían hacer al Estado más efectivo en la distribución de reparaciones. Si bien esto podría tener implicaciones en el plazo de entrega de las reparaciones (puede tomar tiempo desarrollar la infraestructura física, financieray humana requerida para asegurarque se dé un programa de reparación adecuado) "esto puede llevar a reconocer que los beneficios de las reparaciones pueden ser devengados en parte hacia las víctimas

\footnotetext{
12 La concepción del desarrollo utilizada por las autoras lo define "como un proceso que incrementa la prosperidad de una sociedad, aumenta el bienestar de los ciudadanos y construye una infraestructura e instituciones productivas, civiles y políticas necesarias para asegurar a sus miembros una vida lo más plena posible o, por lo menos, con un nivel mínimo de ingreso o de sustento para una vida digna" (Roht-Arriaza \& Orlovsky, 2011, 529). Esta visión se contrapone a la visión clásica del desarrollo económico, mucho más estrecha y enfocada en indicadores de crecimiento económico tales como el PBI per cápita o el volumen de inversión.

13 Sobre la importancia de construir políticas públicas específicas para las víctimas de conflictos armados internos, en especial para población desplazada, ver Ibáñez y Moya (2006, 2009).
} 
iniciales y sobrevivientes de las violaciones y en parte pueden serlo de manera intergeneracional" (2011, p. 528).

En conclusión, un programa de reparaciones bien diseñado e implementado puede jugar un rol importante al cambiar la relación de los ciudadanos con el Estado, en fortalecer efectividad institucional y en crear un mínimo de condiciones para que las víctimas, como sobrevivientes, contribuyan a construir una nueva sociedad.

\section{PROGRAMAS DE REPARACION EN COLOMBIA}

\section{Reparación por vía judicial: la Ley de Justicia y Paz}

Hasta la finalización del proceso de negociación con los paramilitares, el Estado colombiano había dialogado con trece grupos armados organizados al margen de la ley, firmado ocho Acuerdos Humanitarios y de Cese al Fuego, doce Agendas y Acuerdos Preliminares y de Procedimiento y nueve Acuerdos Finales de Paz (Valencia \& Mejía, 2010), sin embargo, ninguno de esos procesos articuló "las herramientas necesarias para la búsqueda de la paz con esquemas de aplicación de la justicia, ni mucho menos de la verdad y la reparacióncomoderechosydeberes" (2010,p. 62). Como otros modelos de JT, el diseño normativo de la Ley de Justicia y Paz - LJP - articula dos sentidos de justicia: la retributiva, "expresada en un mecanismo de alternatividad penal que no debe confundirse, según la sentencia C-370 de la Corte Constitucional, con la amnistía ni con el indulto"; y la restaurativa, "que tiene que ver con el diseño de medidas de reparación individuales y colectivas, planteadas como resarcimiento del daño producido y del sufrimiento

Cuadro 2: perspectivas jurídicas, políticas y económicas de la reparación

\begin{tabular}{|c|c|c|c|c|}
\hline & Uso jurídico & Uso administrativo & Uso político & Uso económico \\
\hline Objetivo & $\begin{array}{l}\text { Restablecer status } \\
\text { quo ex ante de la } \\
\text { víctima en } \\
\text { proporción al daño } \\
\text { sufrido }\end{array}$ & $\begin{array}{l}\text { Reconstruir el Estado } \\
\text { de Derecho, } \\
\text { garantizar el } \\
\text { reconocimiento, la } \\
\text { confianza cívica y la } \\
\text { solidaridad }\end{array}$ & $\begin{array}{l}\text { Transformar status } \\
\text { quo ex ante de la } \\
\text { víctima, } \\
\text { profundización } \\
\text { democrática }\end{array}$ & $\begin{array}{l}\text { Prosperidad social, } \\
\text { bienestar general, } \\
\text { fortalecer } \\
\text { instituciones }\end{array}$ \\
\hline Mecanismos & $\begin{array}{l}\text { Restitución, } \\
\text { indemnización, } \\
\text { rehabilitación, } \\
\text { satisfacción, } \\
\text { garantías de no } \\
\text { repetición }\end{array}$ & $\begin{array}{l}\text { Medidas materiales y } \\
\text { simbólicas, en } \\
\text { relación con otros } \\
\text { mecanismos de la JT. }\end{array}$ & $\begin{array}{l}\text { Restitución, } \\
\text { indemnización, } \\
\text { rehabilitación, } \\
\text { satisfacción, } \\
\text { garantías de no } \\
\text { repetición }\end{array}$ & $\begin{array}{l}\text { Restitución, } \\
\text { indemnización, } \\
\text { rehabilitación, } \\
\text { satisfacción, garantías } \\
\text { de no repetición. } \\
\text { Medidas materiales y } \\
\text { simbólicas }\end{array}$ \\
\hline $\begin{array}{l}\text { Sujeto de } \\
\text { reparación }\end{array}$ & Individuos & Sociedad. & $\begin{array}{l}\text { Individuos, } \\
\text { colectivos, sociedad }\end{array}$ & $\begin{array}{l}\text { Individuos, colectivos, } \\
\text { sociedad }\end{array}$ \\
\hline
\end{tabular}

Fuente: Elaboración propia 
causado por el accionar violento de los grupos paramilitares" (CNMH, 2009, p. 36).

Además de la compensación por los perjuicios causados con los hechos de violencia y victimización - afirman Valencia y Mejía -,

la ley pretende que a las víctimas se les permita retornar a la situación anterior a la comisión del delito, se les ayude a superar los traumas físicos y sicológicos causados, y se difunda la verdad sobre lo sucedido (memoria histórica) y a restablecer la dignidad de las víctimas (individuales y colectivas), mediante la aceptación pública de los hechos, el perdón público, la reconstrucción psico-social de las poblaciones afectadas por la violencia y el restablecimiento de su dignidad; esto, finalmente, con acciones que pretenden garantizar la no repetición de los hechos victimizantes (Valencia \& Mejía, 2010, p. 66).

En ese sentido, la reparación en la LJP comprende los derechos de restitución, indemnización, rehabilitación, satisfacción y garantías de no repetición (Art. 8), tanto en el plano material como en el simbólico y en el individual como en el colectivo. La reparación en la LJP se materializa a través del denominado Incidente de reparación integral, definido en el artículo 23 de la ley. Éste configura la fase final del proceso y tiene lugar una vez que el fiscal del caso ha imputado y legalizado cargos a los "versionados" (paramilitares y guerrilleros postulados a la LJP) y antes de que sea proferida sentencia condenatoria por parte de los magistrados (Cuadro 3). Por esa razón, y dado que su definición y cumplimiento son estrictamente judiciales, "el incidente tiene por objeto reparar únicamente los daños causados por los hechos que la Fiscalía le imputa al versionado, los cuales son apenasun pequeño porcentaje de los hechos cometidos por este" (CNMH, 2009, p. 76).

No obstante, Ibañez y Moya (2006) afirman que si bien la LJP aborda el tema de los derechos de las víctimas a la administración de justicia y a la reparación, la

\begin{tabular}{|c|c|c|c|c|}
\hline \multicolumn{5}{|c|}{ Cuadro 3: Ruta de la escena judicial de la Ley de Justicia y Paz } \\
\hline D & $\begin{array}{l}\mathbf{P} \\
\mathbf{0}\end{array}$ & 1. Etapa investigativa & 2. Etapa probatoria & $\begin{array}{l}\text { 3. Etapa } \\
\text { conciliatoria }\end{array}$ \\
\hline $\begin{array}{l}\text { m } \\
0 \\
\text { v } \\
\text { j } \\
\text { i } \\
\text { i } \\
\text { z } \\
\text { a } \\
\text { c } \\
\text { i } \\
\text { ó } \\
\text { n }\end{array}$ & $\begin{array}{l}\text { t } \\
\text { u } \\
\text { I } \\
\text { a } \\
\text { c } \\
\text { i } \\
\text { ó } \\
\text { n }\end{array}$ & $\begin{array}{l}\text { A. Versiones libres } \\
\text { B. Citación a las víctimas a partir de } \\
\text { lo que se dice en las versiones libres } \\
\text { C. Producción de verdad } \\
\text { D. Procesos de verificación en } \\
\text { campo adelantados por los fiscales }\end{array}$ & $\begin{array}{l}\text { A. Audiencias de imputación y } \\
\text { legalización de cargos a } \\
\text { versionados }\end{array}$ & $\begin{array}{l}\text { A. Incidentes de } \\
\text { reparación }\end{array}$ \\
\hline
\end{tabular}

Fuente: elaboración propia a partir de (CMH, 2009) 
discusión se ha concentrado más en los victimarios y en los elementos que éstos deben aceptar para efectivamente reincorporase a la vida civil, que en las víctimas, sus pérdidas y sus derechos.

Si bien la Ley 975 de 2005 contempla la restitución y la indemnización, los mecanismos para alcanzar dichos objetivos son poco claros y las responsabilidades de los grupos armados al margen de la ley se diluyen en los procesos legales. En primer lugar, la entrega de bienes por parte de los grupos armados para constituir en el Fondo Nacional de Reparación depende de la buena voluntad de dichos grupos, quienes deben indicar los bienes que adquirieron producto de las actividades ilegales. En segundo lugar, la responsabilidad civil de la restitución y la indemnización está supeditada a la sentencia condenatoria de responsabilidad penal. Por último, la asimetría en el poder de negociación de los grupos armados y las víctimas no se corrige con la Ley 975 ni con su Decreto Reglamentario [Decreto 4760 de 2006]. Las víctimas deben acudir de manera individual a solicitar la reparación por parte de los grupos armados al margen de la Ley y cuentan únicamente con el apoyo de Defensores Públicos, mientras los grupos armados cuentan con su organización y con el poder latente de las armas. (Ibañez \& Moya, 2006, p. 6, 7).

Según García (2013), a marzo de 2012 se habían tramitado solo 11 incidentes de reparación judicial en los que estaban incluidas 3.582 víctimas, correspondiente al 0,9 por ciento del total de víctimas registradas, y al 7,7 del grupo de víctimas confesadas. La percepción de la población en general, de las víctimas y de los expertos acerca de los avances en la reparación de las víctimas del conflicto armado ${ }^{14}$ coincide con estos datos (Gráfico 1):

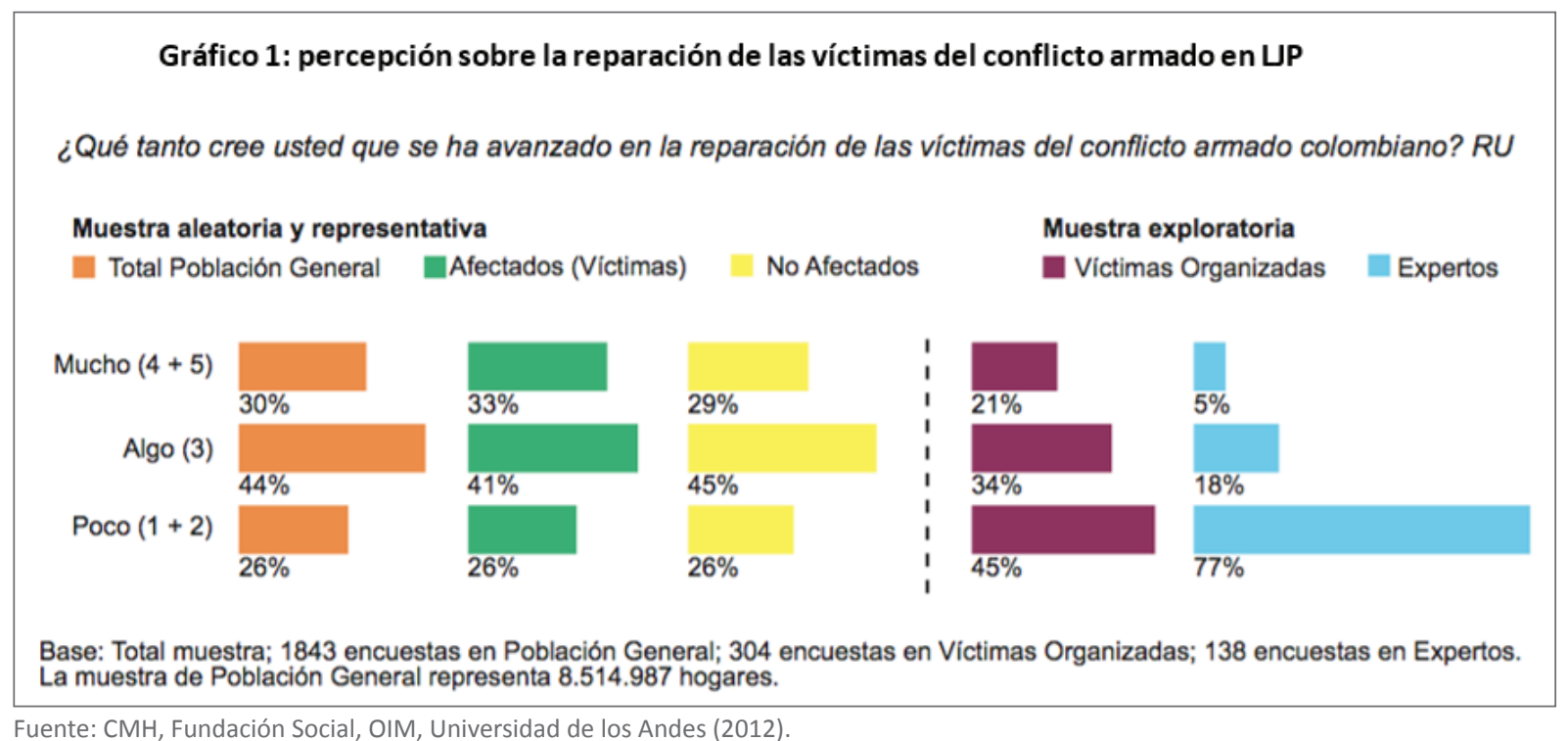

${ }^{14}$ Cifras más actuales aunque no organizadas sobre la reparación en LJP están en http://www.verdadabierta.com/justicia-y-paz/reparacionesa-victimas/6152-los-dilemas-de-la-reparacion-a-las-victimas-en-justicia-y-paz 
De acuerdo con Pizarro (2012), las experiencias de reparaciones exitosas en el plano internacional, la lentitud en los procesos judiciales, la importancia de garantizar universalidad y celeridad, y la necesidad de "conciliar los requerimientos de las políticas de reparación con las capacidades fiscales del Estado" (2012, p. 145), consiguieron que Colombia avanzara hacia un programa de reparación individual por vía administrativa mediante el Decreto 1290 del $2008^{15}$. Una de las características fundamentales de las reparaciones por vía administrativa, según Pizarrro, es que "para lograr que la respuesta a las víctimas sea rápida y universal, no se fundamentan en la tasación de los daños individuales sino en la vulneración de los derechos":

(...) constituye un error confundir la reparación judicial - que se fundamenta en la tasación de daños individuales - con los programas masivos de reparación administrativa que se fundamentan en el resarcimiento por los derechos vulnerados. De ahí que nociones tales como el daño emergente y el lucro cesante no caben en programas administrativos, los cuales no están diseñados para este tipo de tasaciones que son propias de tribunales de justicia. En el marco de la vía administrativa, todas las víctimas de un mismo delito reciben el mismo tipo de medidas reparatorias, con autonomía del tipo de daño individual (Pizarro, 2012, p.149, 150).
Otros autores como Gómez Sánchez (2014) afirman que la aprobación del 1290 se dio como una respuesta desesperada del gobierno de Álvaro Uribe Vélez para contrarrestar la movilización de las víctimas y sus redes de apoyo, que demandaban un nuevo marco jurídico transicional centrado en ellas y su derecho a la reparación integral, y no solamente en los victimarios y el imperativo de su desmovilización ${ }^{16}$. En línea con este argumento, Uprimny y Saffon (2009) han hablado de los "usos manipuladores del discurso de la justicia transicional" de que, en ese contexto, se valieron gobierno y paramilitares para burlar los derechos de las víctimas en la LJP.

\section{Reparación por vía administrativa: la Ley de Víctimas y Restitución de Tierras}

El cambio en las "estructuras de oportunidad" (Gómez Sánchez, 2014) producido en la corriente política (cambio de gobierno, cambio en la composición del Senado) puso en la agenda pública el proyecto impulsado por las redes de apoyo de las víctimas, y condujo finalmente a la institucionalización de sus derechos a la reparación y a la restitución. La reparación se define en la nueva ley como integral, "de tal forma que las víctimas tienen derecho a ser reparadas de manera adecuada, diferenciada, transformadora y efectiva" (ICTJ, 2015, p. 15). Para

\footnotetext{
15 Esfuerzo que seguía siendo a todas luces insuficiente. Siguiendo con García, en el marco de este decreto, a septiembre de 2010, "Acción Social había entregado 396.451 millones de pesos en concepto de reparaciones individuales por vía administrativa, lo que ha significado la reparación de 20.837 familias mediante algunos de sus miembros, con un promedio de 17 millones de pesos entregados a cada uno. (...) Según la Comisión Nacional de Reparación y Reconciliación, durante 2009 se entregaron 12.000 reparaciones individuales. De acuerdo con la información de Acción Social, en 2010 se entregaron 8.837, reduciendo el ritmo de asignación y aumentando el número de víctimas registradas para ese año. En ese sentido, con un promedio anual de asignación de 10.419 reparaciones, estas lograrían cobijar al total de víctimas que aspiran a esta medida indemnizatoria dentro de 29 años" (2013, p. 36, 37)

${ }^{16}$ Según este autor, el Gobierno Uribe veía con preocupación que se iniciara en el Congreso el trámite de un proyecto de ley sobre las "víctimas de crímenes y actos violentos en el marco del conflicto colombiano". La reacción del Gobierno se manifestó de dos formas: "En primer lugar, el mismo presidente Uribe propuso a sus asesores trabajar en la expedición de un decreto reglamentario de la Ley de Justicia y Paz, que había sido expedida tres años antes, con el fin de crear un mecanismo de reparación administrativa" (Gómez Sánchez, 2014, p. 143), es el Decreto 1290, y en segundo lugar, el gobierno se opuso radicalmente al proyecto en el Senado, que ya había sido aprobado en la Comisión Primera y se sometería a debate en plenaria.
} 
este fin, la reparación, además de la indemnización, comprende medidas de restitución, indemnización, rehabilitación, satisfacción y garantías de no repetición, a tono con la clasificación empleada por el derecho internacional. En la práctica, todas estas medidas deben ser desarrolladas en conjunto para tener un impacto en la población beneficiaria. La restitución, por su parte, busca el restablecimiento de las víctimas a la situación en que se encontraban antes de que ocurrieran los hechos violentos. Esto incluye, además de la restitución de tierras, restitución de vivienda, elaboración de proyectos productivos y capacitación para el empleo ${ }^{17}$.

El reconocimiento de estos derechos tuvo que partir del reconocimiento mismo de las víctimas y a su vez, del reconocimiento del conflicto armado, negado sistemáticamente por el anterior gobierno. La Ley de Víctimas y Restitución de Tierras - LVRT - trajo consigo una nueva institucionalidad (distribuida en el nivel subnacional), con un enfoque diferencial, cuyo énfasis se puso en la integralidad de la respuesta estatal, en alusión a la combinación de estrategias económicas, simbólicas, psicológicas, educativas y políticas en la atención a la población sujeta a reparación (Rettberg, 2015).

Por un lado, se reconocen más formas de victimización por un período más largo que el de cualquier otra ley. Así, la fecha acordada desde la cual se cuentan las víctimas en el marco de la ley es el 1 de enero de 1985. Además, el Artículo 3 de la ley reconoce como víctimas a hombres y mujeres, mayores de 18 años, que hayan sido afectados de forma directa por una violación al Derecho Internacional Humanitario (DIH), en el marco del conflicto armado (realizada por grupos armados ilegales y/o agentes del Estado), o que lo haya sido un familiar en primer grado (padres, hijos o hermanos) o su cónyuge o compañero, o el familiar en segundo grado cuando faltan los de primer grado. Por tanto, quedan cubiertas formas de victimización como el homicidio, el secuestro, la desaparición forzada, el reclutamiento forzado y el desplazamiento forzado. (Rettberg, 2015, p. 185).

Portilla y Correa (2015) afirman que las promesas de reparaciones individuales en el marco de la LVRT han sido cumplidas solo parcialmente. Estos autores destacan como un importante logro de la ley los avances en materia de registro de víctimas y de entrega de indemnizaciones ${ }^{18}$, así como la instalación de mesas de víctimas a través de las cuales se canaliza su participación, sin embargo, la naturaleza compleja y ambiciosa de la ley le provee grandes dificultades:

La definición de la reparación como integral, e incluso como transformadora, hace que los objetivos sean difíciles de lograr. La insistencia reciente de caracterizaralareparacióncomo "transformandovidas", cuando ciertamente no tiene capacidad para ello, puede producir más frustración que beneficios. Dadas las dimensiones del conflicto, el elevado número de víctimas y la complejidad de programas y factores, todos descritos con ambiciosos adjetivos, hacen la tarea muy difícil de cumplir, al menos con los elevados estándares definidos (Portilla \& Correa, 2015, p. 1).

Por otra parte, la débil coordinación institucional, la escasa capacidad técnica de las entidades territoriales, los innumerables obstáculos para implementar el enfoque diferencial y las dificultades de reparar en medio del conflicto, han conseguido que la percepción de las víctimas sea de insatisfacción, independientemente de la ejecución del programa. Para estos autores, "existe una alta interdependencia

\footnotetext{
17 Ver ABC Ley de Víctimas y Restitución de Tierras en http://justiciatransicional.gov.co/ABC/Leyvictimas

18 A junio de 2014, destaca el estudio de los autores, se había entregado en total 389.019 indemnizaciones a víctimas por parte de la Unidad de Víctimas, cuyo valor total fue de 2,4 billones de pesos.
} 
entre permanencia del conflicto armado y nivel de satisfacción de las víctimas: a mayor nivel de violencia, mayor nivel de insatisfacción del programa de reparación" $(2015$, p. 2).

Los hallazgos del reciente informe de la Fundación Forjando Futuros - FFF - sobre la restitución de tierras (Cuadro 4) respaldan lo anteriormente expresado: solo el 3,4\% de las solicitudes presentadas por los reclamantes han sido resueltas judicialmente. Esto se explica por la presión que ejercen los actuales ocupantes de los predios, quienes pese a no poder demostrar su "buena fe exenta de culpa" en el $94 \%$ de los casos, se niegan a devolverlos a sus genuinos propietarios.
En materia de satisfacción y de garantías de no repetición, la Encuesta de Goce Efectivo de Derechos 2013 - 2014, realizada por el DANE y la Unidad para la Atención y Reparación Integral a las Víctimas UARIV - aplicada a hogares y personas víctimas de desplazamiento forzado presenta datos interesantes, en la misma dirección del informe sobre la restitución de tierras ${ }^{19}$. Por ejemplo, en satisfacción, el porcentaje de personas víctimas de desplazamiento forzado que han sido objeto de alguna medida como reconocimiento público de los hechos, actos simbólicos, investigación y sanción de los responsables, apoyo en la construcción del tejido social, entre otras, fue de 5,3\%, para el total nacional (Ver gráfico 2 en anexos). Sobre garantías de no

\begin{tabular}{|c|c|}
\hline \multicolumn{2}{|c|}{ Cuadro 4: Cifras de la restitución de tierras con corte al 1 de abril de 2016* } \\
\hline Solicitudes presentadas & 87.118 \\
\hline Sentencias de Restitución & 1.500 \\
\hline Solicitudes Resueltas judicialmente** & 2.943 \\
\hline Hectáreas & 197.927 \\
\hline Predios & 2.645 (2.567 rurales +78 urbanos) \\
\hline Personas beneficiadas & 2.896 mujeres (51\%) y 2.751 hombres (49\%) \\
\hline $\begin{array}{r}\text { Indígenas beneficiados con restitución } \\
\text { colectiva }\end{array}$ & $\begin{array}{l}\text { Alto Andagueda: } 31 \text { comunidades, } 1.456 \text { familias, } \\
7.270 \text { personas }\end{array}$ \\
\hline $\begin{array}{r}\text { Afrodescendientes beneficiados con } \\
\text { restitución colectiva }\end{array}$ & $\begin{array}{l}\text { Renacer Negro Timbiquí: } 9 \text { comunidades, } 762 \\
\text { familias, } 5.472 \text { personas }\end{array}$ \\
\hline
\end{tabular}

19 La cobertura de la encuesta es nacional dividida en 12 subregiones: Antioquia, Eje cafetero, Tolima grande, Valle del Cauca, Nuevos departamentos, Boyacá, Santanderes, Pacífica, Costa B, Bogotá D.C, Costa A, Costa C. La encuesta se aplicó a 27.727 hogares y 112.406 personas. 
repetición, la encuesta deja ver que $76,0 \%$ de las personas desplazadas no fueron revictimizadas después del hecho de desplazamiento (Ver gráfico 3 en anexos).

\section{Hacia un Sistema Integral de Verdad, Justicia, Reparación y No Repetición - SIVJRNR -}

Las dos características fundamentales del acuerdo de víctimas entre la guerrilla de las Farc-Ep y el gobierno nacional, son, por un lado, su vocación de sistema, que apunta a que los distintos mecanismos que vehiculan los principios de la justicia transicional - JT - sean implementados de manera coordinada e interconectada, sin que implique un solapamiento de funciones ni algún tipo de superioridad de unos mecanismos sobre otros. Y por el otro lado, la centralidad que ocupan las víctimas, o, lo que es lo mismo, el imperativo de resarcirlas y reconocerlas como "sujetos de derechos". La consideración de estos dos aspectos comprende un concepto de justicia ampliado, en el que la perspectiva retributiva es alimentada por perspectivas de justicia restaurativa y reparadora, bases fundamentales de la reparación.

Las medidas acordadas para la reparación integral en el SIVJRNR ${ }^{20}$ incluyen los derechos a la restitución, la indemnización, la rehabilitación, la satisfacción y la no repetición, acatando la clasificación empleada por el derecho internacional; con especial énfasis en la reparación colectiva de los territorios, las poblaciones y los colectivos más afectados por el conflicto. Estas medidas, más que constituir una nueva arquitectura institucional para las víctimas, están llamadas a fortalecer los mecanismos ya existentes, institucionalizados a través de la LVRT (algunas de ellos creados con la aprobación de la LJP). Se consideran medidas para la reparación integral: a) los actos públicos de reconocimiento de responsabilidad colectiva, incluyendo al Estado; b) las acciones concretas de contribución a la reparación, como el esclarecimiento de la verdad y el desarme, la desmovilización y la reintegración - DDR; c) los planes nacionales y territoriales de reparación colectiva, incluyendo los Planes de Desarrollo Rural con Enfoque Territorial - PDET; d) los programas de recuperación emocional a nivel individual y los planes de rehabilitación psico-social para la convivencia y la no repetición; e) los procesos colectivos de retorno enfocados a personas en condición de desplazamiento y víctimas en el exterior; f) medidas para la restitución de tierras.

\section{CONCLUSIONES}

No pocas voces han advertido sobre el rol determinante que juega el Acuerdo de Víctimas para las negociaciones de La Habana y en la terminación definitiva del conflicto armado. Por un lado, sobre él prácticamente se construye la posibilidad de que los jefes de la guerrilla puedan participar en política ${ }^{21}$. Por el otro, el Acuerdo está prácticamente obligado a corregir los impasses de las experiencias, si no fallidas sí bastante discretas, de justicia y paz y de la ley víctimas y restitución de tierras, en materia de reparaciones. Esto último con dos agravantes: 1. un contexto de déficit en las finanzas del Estado que sin duda generará más talanqueras al desarrollo de los procesos de indemnización judicial y administrativa, 2 . una oposición cada vez más enconada, legal e ilegal, política y militar, al proceso de restitución de tierras. 
Lo que se debate, de nuevo, es si, de nuevo, asistimos simplemente a la implementación de un nuevo modelo de justicia transicional sin transición (Uprimny \& Saffon, 2009) como el que se negoció con los paramilitares, o si, por el contrario, podremos transitar definitivamente de la guerra a la paz. El punto que he querido resaltar hasta acá es que en una reparación exitosa reside la base más firme de esa posibilidad. Por lo pronto, algunos nudos deben desatarse:

\section{Reparación judicial o administrativa: ¿Sólo una aclaración semántica?}

La tremenda discusión que se suscitó tras la aprobación de la Ley 1592 de 2012, que reformó la LJP, es revelador en este sentido. La reforma pretendió cerrar la puerta a las reparaciones por la vía de la LJP, y centrarla en la LVRT, a través de la eliminación del "Incidente de reparación integral" (Art. 23, LJP) sustituyéndolo por el "Incidente de identificación de las afectaciones", lo cual comprometió sustituir la reparación judicial en un proceso penal por una administrativa (determinada en una tabla con valores fijos). Las implicaciones de la medida en materia económica fueron determinantes, dado que, según el criterio de los especialistas, los montos de las reparaciones de las víctimas por vía administrativa, por ejemplo en el caso de homicidio, representan apenas el cinco por ciento del que los jueces de Justicia y Paz asignan conforme a los métodos de tasación que han desarrollado (Gallón, 2014). El debate político y jurídico que suscitó la medida, indica que lo "judicial" y lo "administrativo" en las reparaciones no hace alusión a un simple apellido, sino que comporta hondas implicaciones, de forma y de fondo. Aunque la Corte Constitucional mediante sentencia C-180 de 2014, restableció el "incidente de reparación integral" el debate se mantiene, fundamentalmente en materia de indemnización económica.

\section{¿A cuenta de quién la borrachera?}

Lo anterior, en un contexto en el que el Estado, como subsidiario, ha tenido que asumir casi por entero el costo de la reparación de las víctimas. De acuerdo con el portal Verdad Abierta, solamente el 6 por ciento de las reparaciones se han pagado con lo que entregaron los postulados a la ley. En cifras, con corte a 28 de febrero de 2016, según el informe del Fondo para las Reparaciones de la UARIV, de los más de 73 mil millones de pesos que se han pagado en materia de indemnización judicial a las víctimas de justicia y paz, 4.594 han salido de los recursos propios de los postulados, mientras que más de 65 mil han sido pagados con presupuesto general de la nación. En materia de indemnización administrativa, fueron asignados por el Conpes de la LVRT (Conpes 3712 de 2011) cerca de 6,4 billones de pesos que se distribuyeron de la siguiente forma: 863.000 millones para el 2012 y 615.000 millones para los restantes 9 años de vigencia de la ley. Con corte a junio de 2014, se habían entregado un total 389.019 indemnizaciones a víctimas, cuyo valor total asciende a 2,4 billones de pesos. Pese a que el Estado hace esfuerzos enormes

\footnotetext{
${ }^{21}$ La La visión "despolitizada" de la escena judicial provista en el denominado Marco Jurídico para la Paz tuvo que ceder paso al reconocimiento del delito político en la Jurisdicción Especia para la Paz, por medio de la incorporación de una Sala de Amnistía e Indulto. Esta fue una concesión a las FARC dado que se les reconoció como actor político en la mesa, bajo la promesa de que posterior a su desmovilización podrán ingresar a la competencia política institucional, máxime cuando ya se había negociado un acuerdo sobre participación. Lo anterior le permitirá al grupo guerrillero aparecer como sujeto político en la escena judicial. Y dado que, en concordancia con ello, la imputación de responsabilidades no se descargará sobre los máximos responsables, sino que se "administrará" de acuerdo a la comprobación de la participación determinante en los hechos, el secretariado de las Farc no solamente se libra de la judicialización, sino que podrá participar "libremente" en política electoral.
} 
por reparar, es claro que el estado deficitario de sus finanzas promete perpetuar el estado de insatisfacción de las víctimas, tanto por los incumplimientos en los pagos de aquellas que ya tienen sentencia judicial a su favor, como por el rezago a que debido al largo plazo de distribución de pagos por vía administrativa.

Aunque la respuesta a la pregunta sobre si la reparación de las víctimas debe quedar a cargo de los perpetradores y no del Estado es obvia, el punto es cómo obligarlos a que reparen, más allá de lo puramente simbólico, máxime cuando paramilitares y guerrilleros por igual se declaran en banca rota. Por otra parte, ¿Los "civiles" que se han beneficiado de la guerra, que han participado de ella como auspiciadores y financiadores, deben contribuir a la reparación? Si bien la integralidad del sistema pactado en La Habana contempla que terceros sean llamados ante la Jurisdicción Especial para la Paz y la Comisión para el esclarecimiento de la verdad, la convivencia y la no repetición, no está claro de qué manera aportarías a las medidas de reparación integral para la construcción de paz.

\section{¿Resignarse ante el despojo?}

No se sabe a ciencia cierta cuántos millones de hectáreas de tierra han sido despojadas y/o abandonadas con ocasión del conflicto armado en Colombia. Se sabe que no son menos de 4 y que la suma podría ascender a 10. En 2012, las cifras oficiales apuntaban a 6,5 millones de hectáreas. De acuerdo con el informe citado anteriormente (Cuadro 4), a cinco años de implementación de la LVRT, han sido restituidas 197.927, no más del 3,4\% del despojo. A pesar del esfuerzo de la UARIV, y de la Oficina de Restitución de Tierras, poderosas fuerzas legales e ilegales, se oponen al desarrollo de la ley y a que las víctimas puedan retornar a sus predios. Mientras que, políticamente, las organizaciones antirestitución de tierras reciben respaldo de dirigentes gremiales, partidos políticos de ultraderecha y hasta de la Procuraduría General de la Nación, militarmente han contado con el respaldo indirecto de paramilitares que intimidan, amenazan y asesinan a los reclamantes de las tierras. Según cifras oficiales, desde 2011 cuando entró en vigencia la ley, se han registrado 12 asesinatos de reclamantes directos, sin contar los líderes sociales que ha apoyado indirectamente la brega de estos. Si bien las medidas sobre restitución de tierras acordadas en La Habana tratan de vincularla tanto a la reparación colectiva (a través de los PDET) como a la Reforma Rural Integral acordada en la misma mesa (que apunta a resolver el problema de la informalidad en los títulos de propiedad, y además actualizar y modernizar el catastro rural) los mecanismos diseñados e implementados parecen insuficientes, o por lo menos, sin la suficiente "voluntad política" para enfrentar el fenómeno masivo, y extraordinariamente brutal, de "acumulación por desposesión" (Harvey, 2003) que caracteriza esta arista del conflicto colombiano.

\section{REFERENCIAS}

Arthur, P. (2011). Cómo las "transiciones" reconfiguraron los derechos humanos: una historia conceptual de la justicia transicional. En, F. Reátegui (Ed.) Justicia transicional. Manual para América Latina. New York-Brasilia: Centro Internacional para la Justicia transicional, Comisión de Amnistía, Ministerio de Justicia de Brasil

Centro de Memoria Histórica. (2009). Justicia y paz. ¿Verdad judicial o verdad histórica? Bogotá: $\mathrm{CMH}$, Semana, Taurus. 
Centro de Memoria Histórica, Fundación Social, OIM, Universidad de los Andes. (2012). Encuesta Nacional: ¿Qué piensan los colombianos después de siete años de Justicia y Paz? Bogotá: $\mathrm{CMH}$.

Comisión Colombiana de Juristas. (2007). Principios Internacionales sobre impunidad y reparaciones. Bogotá: Ediciones Gráficas

DANE, UARIV. (2015). Informe Encuesta de Goce Efectivo de Derechos. Declaración y programa de acción de Viena. Conferencia mundial de derechos humanos. (1993). Tomado de http://www.ohchr.org/Documents/ Events/OHCHR20/VDPA_booklet_Spanish.pdf Decreto 1290 de 2008. Diario Oficial 46.968

De Greiff, P. (2011). Justicia y reparaciones. En, F. Reátegui (Ed.) Justicia transicional. Manual para América Latina. New York-Brasilia: Centro Internacional para la Justicia transicional, Comisión de Amnistía, Ministerio de Justicia de Brasil

Fondo para la Reparación de las Víctimas. Unidad para la Atención y la Reparación Integral de las Víctimas (2016). Informe ejecutivo.

Fundación Forjando Futuros. (2016). Restitución de tierras no avanza. Documento digital. Recuperado el 1 de mayo de 2016. Tomado de:

http://forjandofuturos.org/documentos/publicacion-restitucion-de-tierras-no-avanzas_1500-sentencias_abril-2016-fundacion-forjando-futuros-version-web.pdf

Gallón, G. (2014). Reparando las reparaciones. Columna de opinión en El Espectador. Recuperado el 6 de mayo de 2016
García, J.F. (2013). El lugar de las víctimas en Colombia. Bogotá: Universidad Javeriana, CITpax, Editorial Temis.

Gómez Sánchez, G. (2014). Justicia transicional en disputa. Una perspectiva constructivista sobre las luchas por la verdad, la justicia y la reparación en Colombia, 2002 - 2012. Medellín: Editorial Universidad de Antioquia

Harvey, D. (2003). The new imperialism. Oxford: Oxford University Press.

Ibañez, A.M. (2008). El desplazamiento forzoso en Colombia: ¿Un camino sin retorno a la pobreza? Bogotá: Universidad de Los Andes, Facultad de Economía, CEDE

Ibañez, A.M \& Moya, A. (2006). ¿Cómo el desplazamiento forzado deteriora el bienestar de los hogares desplazados?: Análisis y determinantes del bienestar en los municipios de recepción. Documento CEDE 2006-26.

Ibáñez, A. M. \& Moya, A. (2009). Do conflicts create poverty traps? Asset losses and recovery for displaced households in Colombia. MICROCON Research Working Paper 10, Brighton: MICROCON.

Informe del Relator Especial sobre la promoción de la verdad, la justicia, la reparación y las garantías de no repetición, Pablo de Greiff. (2012). http://www.ohchr. org/Documents/HRBodies/HRCouncil/RegularSession/ Session21/A-HRC-21-46_sp.pdf

Informe del Secretario General sobre el Estado de Derecho y la Justicia de Transición en las sociedades que sufren o han sufrido conflictos. (2004). http://www.un.org/es/comun/docs/?symbol=S/2004/616 
Informe final revisado acerca de la cuestión de la impunidad de los autores de violaciones de los derechos humanos (derechos civiles y políticos) preparado por el Sr. L. Joinet de conformidad con la resolución 1996/119 de la Subcomisión. Doc.

ONU E/CN.4/Sub.2/1997/20/Rev.1

Ley 975 de 2005. Diario Oficial 45.980

Ley 1448 de 2011. Diario Oficial 48.096

Orozco, I. (2009). Justicia transicional en tiempos del deber de memoria. Bogotá: Temis, Universidad de los Andes.

Orozco, I. (2002). Venganza, justicia y reconciliación. En, Análisis político, N. 46, pp. 78 - 100

Principios y directrices básicos sobre los derechos de las víctimas de violaciones manifiestas de las normas internacionales de derechos humanos y violación al derecho internacional humanitario a interponer recursos y obtener reparaciones

Pizarro, E. (2012). Bases para una política de reparación en Colombia viable, justa y sostenible. En, A. Rettberg (Comp.) Construcción de paz en Colombia. Bogotá: Universidad de los Andes.

Portilla, A. C., \& Correa, C. (2015). Estudio sobre la implementación del Programa de Reparación Individual en Colombia. Centro Internacional para la Justicia Transicional (ICTJ).

Roht-Arriaza, N. \& Orlovsky, K. (2011). Reparaciones y desarrollo: una relación complementaria. En, F. Reátegui

(Ed.) Justicia transicional. Manual para América Latina. New York-Brasilia: Centro Internacional para la Justicia transicional, Comisión de Amnistía, Ministerio de Justicia de Brasil
Santamaría, A. (2014). Formas de reparación a las víctimas de violación de los Derechos Humanos en el Derecho Internacional y efectos en la Ley de Justicia y Paz en Colombia. En, Y. Sierra (Comp.). Conversatorios de Arte y Derechos Humanos. Boletín número 1. Bogotá: Universidad Externado de Colombia

Uprimny, R. \& Saffon, M. (2009). Reparaciones transformadoras, justicia distributiva y profundización democrática. En, C. Díaz, N. Sánchez, R. Uprimny (Eds). Reparar en Colombia: los dilemas en contextos de conflicto, pobreza y exclusión. Bogotá: Centro Internacional para la Justicia Transicional (ICTJ) y Centro de Estudios de Derecho, Justicia y Sociedad (DeJuSticia).

Uprimny, R. \& Saffon, M. (2009). Usos y abusos de la justicia transicional en Colombia. En, A. Rangel (Ed.). Justicia y paz ¿Cuál es el precio que debemos pagar? Bogotá: Editorial Intermedio

Valencia, D., \& Mejía, C. (2010). Ley de Justicia y Paz, un balance de su primer lustro. Perfil de Coyuntura Económica No. 15, pp. 59-77

Van Boven, T. (2010). Principios y directrices básicos de las naciones unidas sobre el derecho de las víctimas de violaciones manifiestas de las normas internacionales de derechos humanos y de violaciones graves del derecho internacional humanitario a interponer recursos y obtener reparaciones. United Nations Audiovisual Library of International Law

Citar este artículo como: Tafur, A. (2017). "El deber de reparar en contextos extraordinarios y transicionales". En: Revista La Tercera Orilla (18). Bucaramanga: Universidad Autónoma de Bucaramanga. 
Tabla 1: Informes y documentos relativos al derecho de restitución, indemnización y rehabilitación de las víctimas de violaciones graves de los ddhh y las libertades fundamentales - ONU.

\begin{tabular}{|c|c|c|}
\hline Informe & Relator & Identificación \\
\hline $\begin{array}{l}\text { Estudio relativo al derecho de restitución, indemnización y } \\
\text { rehabilitación a las víctimas de violaciones flagrantes de los } \\
\text { derechos humanos y las libertades fundamentales }\end{array}$ & $\begin{array}{l}\text { Theo van Boven } \\
(1993)\end{array}$ & $\begin{array}{l}\text { Doc. ONU } \\
\text { E/CN.4/Sub.2/1993/8 }\end{array}$ \\
\hline $\begin{array}{l}\text { La administración de justicia y los derechos humanos. Serie } \\
\text { revisada de principios y directrices sobre el derecho de las } \\
\text { víctimas de violaciones graves a los derechos humanos y al } \\
\text { derecho humanitario a obtener reparación }\end{array}$ & $\begin{array}{l}\text { Theo van Boven } \\
(1996)\end{array}$ & $\begin{array}{l}\text { Doc. ONU } \\
\text { E/CN.4/Sub.2/1996/17 }\end{array}$ \\
\hline $\begin{array}{l}\text { Revisión de los Principios y directrices básicos sobre el } \\
\text { derecho de las víctimas de violaciones a los derechos } \\
\text { humanos y al derecho internacional humanitario a obtener } \\
\text { reparación. }\end{array}$ & $\begin{array}{l}\text { Theo van Boven } \\
(1997)\end{array}$ & $\begin{array}{l}\text { Doc. ONU } \\
\text { E/CN.4/1997/104 }\end{array}$ \\
\hline $\begin{array}{l}\text { Informe sobre el derecho de restitución, indemnización y } \\
\text { rehabilitación de las víctimas de violaciones graves de los } \\
\text { derechos humanos y las libertades fundamentales, de } \\
\text { conformidad con la resolución 1998/43 de la Comisión de } \\
\text { Derechos Humanos. }\end{array}$ & $\begin{array}{l}\text { Cherif Bassiouni } \\
(1999)\end{array}$ & $\begin{array}{l}\text { Doc. ONU } \\
\text { E/CN.4/1999/65 }\end{array}$ \\
\hline $\begin{array}{l}\text { El derecho de restitución, indemnización y rehabilitación de } \\
\text { las víctimas de violaciones graves de los derechos humanos y } \\
\text { las libertades fundamentales, en virtud de la resolución } \\
\text { 1999/33 de la Comisión. }\end{array}$ & $\begin{array}{l}\text { Cherif Bassiouni } \\
(2000)\end{array}$ & $\begin{array}{l}\text { Doc. ONU } \\
\text { E/CN.4/2000/62 }\end{array}$ \\
\hline $\begin{array}{l}\text { Resolución sobre el derecho de restitución, indemnización y } \\
\text { rehabilitación de las víctimas de violaciones graves de los } \\
\text { derechos humanos y las libertades fundamentales, número } \\
\text { 2002/44 de la Comisión de Derechos Humanos }\end{array}$ & $\begin{array}{l}\text { Comisión de } \\
\text { ddhh ONU } \\
(2002)\end{array}$ & $\begin{array}{l}\text { Doc. ONU } \\
\text { E/CN.4/RES/2002/44 }\end{array}$ \\
\hline $\begin{array}{l}\text { El derecho de las víctimas de violaciones de las normas } \\
\text { internacionales de derechos humanos y del derecho } \\
\text { humanitario a interponer recursos y obtener reparaciones. } \\
\text { (1) }\end{array}$ & $\begin{array}{l}\text { Alejandro } \\
\text { Salinas (2003) }\end{array}$ & $\begin{array}{l}\text { Doc. ONU } \\
\text { E/CN.4/2003/63 }\end{array}$ \\
\hline $\begin{array}{l}\text { El derecho de las víctimas de violaciones de las normas } \\
\text { internacionales de derechos humanos y del derecho } \\
\text { humanitario a interponer recursos y obtener reparaciones. } \\
\text { (2) }\end{array}$ & $\begin{array}{l}\text { Alejandro } \\
\text { Salinas (2004) }\end{array}$ & $\begin{array}{l}\text { Doc. ONU } \\
\text { E/CN.4/2004/57 }\end{array}$ \\
\hline $\begin{array}{l}\text { El derecho de las víctimas de violaciones de las normas } \\
\text { internacionales de derechos humanos y del derecho } \\
\text { humanitario a interponer recursos y obtener reparaciones. } \\
\text { (3) }\end{array}$ & $\begin{array}{l}\text { Alejandro } \\
\text { Salinas (2005) }\end{array}$ & $\begin{array}{l}\text { Doc. ONU } \\
\text { E/CN.4/2005/59 }\end{array}$ \\
\hline $\begin{array}{l}\text { Resolución 2005/35 de la Comisión de Derechos Humanos, } \\
\text { por la cual se aprueban los Principios y directrices... }\end{array}$ & $\begin{array}{l}\text { Comisión de } \\
\text { ddhh ONU } \\
(2005)\end{array}$ & $\begin{array}{l}\text { Doc. ONU } \\
\text { E/CN.4/RES/2005/35 }\end{array}$ \\
\hline $\begin{array}{l}\text { Resolución } 2005 / 30 \text { del Consejo Económico y Social (que } \\
\text { aprueba y recomienda a la Asamblea General la aprobación } \\
\text { de los Principios y directrices básicos) }\end{array}$ & $\begin{array}{l}\text { Consejo } \\
\text { Económico y } \\
\text { Social ONU } \\
(2005)\end{array}$ & $\begin{array}{l}\text { Doc. ONU ECOSOC Res. } \\
2005 / 30\end{array}$ \\
\hline
\end{tabular}

Fuente: Elaboración propia a partir de Comisión Colombiana de Juristas (2007) 